\title{
NUMERICAL STUDY OF THE CHARACTERISTICS OF THE AIR CONDENSER SECTION
}

\author{
Galashov Nikolay ${ }^{1,}$, Tsibulskiy Svyatoslav $^{1}$, Gubin Vladimir $^{1}$, Serova Tatiana $^{1}$ \\ ${ }^{1}$ National Research Tomsk Polytechnic University, Institute of Power Engineering, 634050 Tomsk, Russia
}

\begin{abstract}
Relevance of the work is due to the need to create a mathematical model of thermal processes in the air condenser section (AC). The purpose of the work is to the development and testing a mathematical model applied to the section AC condensation of low-boiling substances used as working materials in the organic Rankine cycle. A mathematical model was developed, and allows complex investigations that involve a change in the type of working material and geometric and operational parameters section AC. For the calculation of thermal parameters using a database of properties of substances «REFPROP». On the basis of the mathematical model in Excel spreadsheet package developed a program for calculating the parameters and performance measures of AC. The numerical model studies have shown that the characteristics and performance indicators $\mathrm{AC}$ highly dependent on the type of substance. When changing external air temperature from -40 to $40{ }^{\circ} \mathrm{C}$ heat flux in the AC falls to $175 \div 185 \mathrm{~W} / \mathrm{m}^{2}$. The model allows to determine the number of sections and investments in the condenser of the known heat flow. Heat flow must be selected based on outdoor temperature taking into account the climatic conditions of the AC.
\end{abstract}

\section{Introduction}

The use air condensers in the thermal power plants can significantly reduce water consumption, prevent pollution and salt saturation of air with water vapor [1,2].

Since the 70s of the last century, the AC have been used on the powerful steam-turbine power units in countries such as the US, Germany, France, South Africa, Netherlands, Spain [1]. Recently, foreign the $\mathrm{AC}$ began to be applied to the combined cycle plant (CCP) power from 150 to $850 \mathrm{MW}$ in the United States, the UK, Belgium, Italy, Mexico, Algeria, Bahrain and coal-fired supercritical steam power units with capacity of 600 and $660 \mathrm{MW}$ in China. In Russia, the AC is set to "VerhneMutnovskaya» Geothermal Power Plant, TPP of Sochi, Adler TPP and «Pervomayskaya» CHP.

A significant increase in the efficiency of the application of the AC is available at CCGT triple loop [3] when installing them in the northern regions of Russia, where most areas are located in gas production, and outdoor temperature is below $0{ }^{\circ} \mathrm{C}$ are 7-8 months of the year.

When the the AC to steam main problem is that they have large dimensions. This can be explained by the fact that due to the low density of steam at low pressures, and in winter condensation a risk of freezing and discontinuity the pipes.

\footnotetext{
${ }^{a}$ Corresponding author: gal@tpu.ru
} 


\section{Parameters section of the AC}

Modern AC are assembled from standard commercially produced sections [4]. Several sections are combined into the module. The fan pumps air through the module. Pipe system consists of two sections and collectors multiple rows of finned tubes (Fig. 1). The main sections geometrical parameters are: the length of the pipe $L$; the width of the tube bundle $B$; the total number of pipes $N$; the number of rows of pipes in the section of the air flow $Z$. The layout of the pipe section and the geometric parameters are shown in Fig. 2 where $S_{1}$ - transverse pitch pipes; $S_{2}$ - step between the rows of tubes in the direction of air flow; $d$ - diameter of the pipe ribs; $h$ - height of the ribs; $d_{\text {out }}, d_{i n}-$ outer and inner diameter of the pipe; $\delta$ - pipe wall thickness; $\Delta-$ the thickness of the ribs; $S$ - step edges.

The aim is to create a mathematical model of the numerical sections AC allows investigation condensation steam of different substances when changing the geometric parameters of the section and tube bundle temperature and air velocity, temperature, condensation of matter.
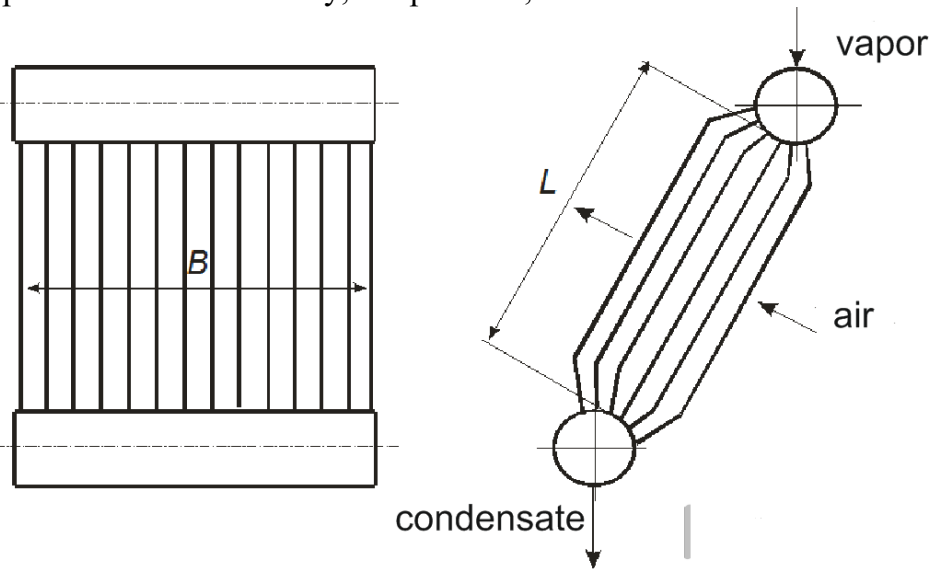

Figure 1. Pipe system of the sections
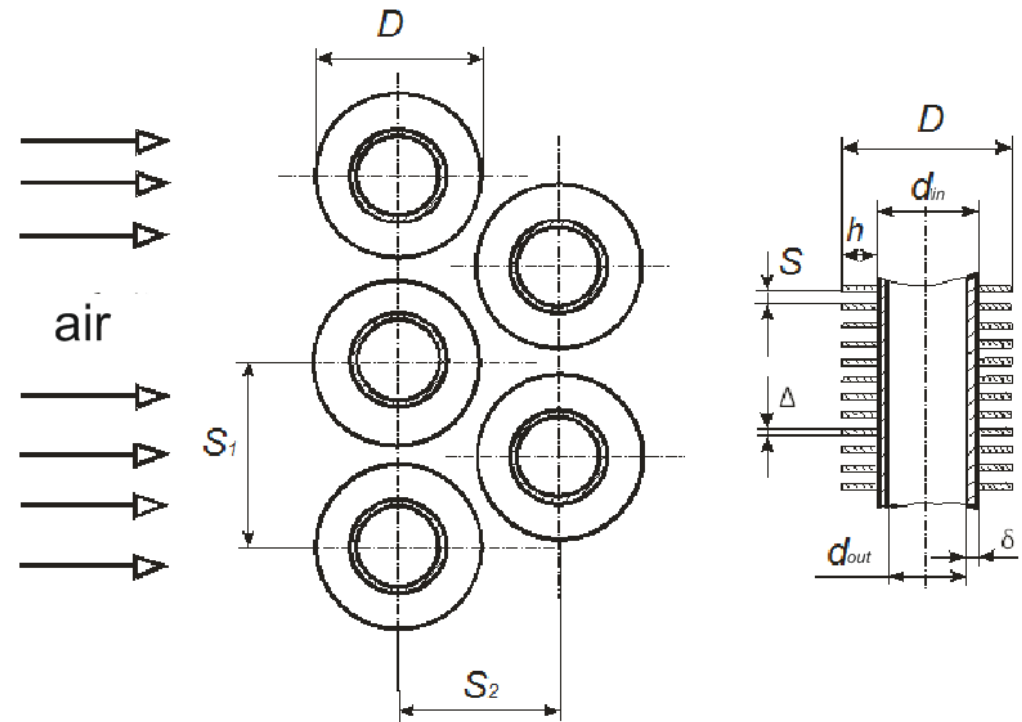

Figure 2. The layout of and geometric parameters of the pipe section 


\section{Investigation of AC's characteristics on a mathematical model}

The mathematical model is based on the methods described in [4]. The initial data are given sections geometric parameters: $L ; B ; N ; Z$; pipe material and edges and geometric parameters in m: $S_{1} ; S_{2} ; D$; $h ; d_{\text {out }} ; d_{\text {in }} ; \delta ; \Delta ; S$, as well as the operating parameters: temperature of the air entering the section $t_{\text {o.a. }}$ ${ }^{\circ} \mathrm{C}$; barometric pressure $p_{\mathrm{b}} \mathrm{kPa}$; air velocity in the narrowest section of sections $\omega_{\text {air }} \mathrm{m} / \mathrm{s}$; condensing temperature substances $\mathrm{t}_{\mathrm{C}}{ }^{\circ} \mathrm{C}$; its degree of dryness at the input $x_{1}$ and output $x_{2}$ section.

Simplified algorithm for calculating the sections AC in the following models:

1. As determined by the $t_{C}$ of the condensing pressure $\mathrm{p}_{\mathrm{C}}, \mathrm{MPa}$.

2. Takes the average temperature in the section:

$$
t_{\text {a.a. }}=\left(t_{\text {int }}+t_{\mathrm{C}}-10\right) / 2 .
$$

3. Takes consumption of steam entering the section, $\mathrm{kg} / \mathrm{s} \mathrm{G}_{\mathrm{s}}$.

4. The rate of steam inlet pipe sections:

$$
\omega_{\mathrm{S}}=G_{\mathrm{S}} /\left(F_{\mathrm{S}} \cdot \rho_{\mathrm{S}}\right), \mathrm{m} / \mathrm{s}
$$

where the steam density $\rho_{\mathrm{S}}$ determined by $p_{\mathrm{C}}$ and $x_{\text {int }}$.

5. The heat flow from the steam to the air:

$$
Q=G_{\mathrm{S}}\left(h_{\text {int }}-h_{\text {out }}\right), \mathrm{m} / \mathrm{s},
$$

where enthalpies $h_{\text {int }}, h_{\text {out }}$ determined by $p_{\mathrm{C}}, x_{\text {int }}, x_{\text {out }}$.

6. The specific heat flow through the unit ribbed surface:

$$
q=Q / F, \mathrm{~W} / \mathrm{m}^{2} \text {. }
$$

7. Air flow rate:

$$
V=\chi \cdot \omega_{\text {air }} \cdot L \cdot B, \mathrm{~m}^{3} / \mathrm{s},
$$

where $\chi=1-\left[1+2 h \cdot \Delta / d_{\mathrm{H}} \cdot S\right] \mathrm{d}_{0} / \mathrm{S}_{1}-$ the compression ratio of air flow.

8 . The mass air flow:

$$
G_{\text {air }}=V \rho_{\text {air }}, \mathrm{kg} / \mathrm{s},
$$

where $\rho_{\text {air }}-$ density of air determined by $t_{\text {a.a }}$ и $p_{\mathrm{b}}$.

9. Air heating in the section:

$$
\Delta t_{\text {air }}=Q /\left(G_{\text {air }} \cdot c_{\text {air }}\right),{ }^{\circ} \mathrm{C},
$$

where the heat capacity of the air determined by $c_{\text {air }}$ при $t_{\text {a.a }}$ и $p_{\mathrm{b}}$.

10. The air temperature at the output of sections:

$$
t_{\text {air } 2}{ }^{\prime}=t_{\text {o.a }}+\Delta t_{\text {air }},{ }^{\circ} \mathrm{C} .
$$

11. The average temperature in the section:

$$
t_{\text {a.a. }}=\left(t_{\text {o.a. }}+t_{\text {air } 2}{ }^{\prime}\right) / 2,{ }^{\circ} \mathrm{C} .
$$

12. The final temperature difference:

$$
\theta=t_{\mathrm{C}}-t_{\mathrm{air} 2}{ }^{\prime},{ }^{\circ} \mathrm{C}
$$

13. Temperature head section: 


$$
\Delta t=\left(t_{\text {air2 }}{ }^{\prime}-t_{\text {нв }}\right) / \ln \left(\left(t_{\mathrm{K}}-t_{\text {о. } . \text {. }}\right) /\left(t_{\mathrm{C}}-t_{\text {air } 2}{ }^{\prime}\right)\right),{ }^{\circ} \mathrm{C} .
$$

14. Heat-exchange coefficient inside the tube:

$$
\alpha_{\mathrm{S}}=\mathrm{Nu}_{\text {average }} \cdot \lambda_{\mathrm{C}} / \mathrm{d}_{\mathrm{int}}, \mathrm{W} /\left(\mathrm{m}^{2} \mathrm{~K}\right),
$$

where for calculating the average heat-exchange coefficient from the condensing steam to the inner wall of the pipe used equation [5]

$$
\mathrm{Nu}_{\text {average }}=C \cdot \operatorname{Re}_{\mathrm{C}}^{0,8} \cdot \operatorname{Pr}_{\mathrm{C}}^{0,43} \cdot 0,5\left[\sqrt{1+x_{\text {int }} \cdot\left(\frac{\rho_{\mathrm{C}}}{\rho_{\mathrm{S}}}-1\right)}+\sqrt{1+x_{\text {out }} \cdot\left(\frac{\rho_{\mathrm{C}}}{\rho_{\mathrm{S}}}-1\right)}\right],
$$

where $C$ - coefficient depending on the type of pipe material: 0.024 - steel, 0.026 for brass and 0.032 - for copper; $\mathrm{Nu}$ - Nusselt number; $\mathrm{Re}$ - Reynolds number; $\mathrm{Pr}$ - Prandtl number; $\rho_{\mathrm{C}}, \rho_{\mathrm{S}}-$ condensate density and a couple of substance. The advantage of this equation is that when $\operatorname{Re}_{C}>5 \times 10^{3}$ angle pipe does not affect the rate of heat transfer, where the Reynolds number is defined as $\operatorname{Re}_{\mathrm{C}}=4 \mathrm{G}_{\mathrm{S}} /\left(\pi d_{\text {in }} \mu_{\mathrm{C}}\right)$ where $\mu_{\mathrm{C}}$ - the coefficient of dynamic viscosity condensate. All the physical parameters in the number $\mathrm{Nu}, \mathrm{Re}$ and $\mathrm{Pr}$, as well as the density of condensate and steam are defined by the saturation temperature.

15. The heat-exchange coefficient from the finned surface of the pipe to the air:

$$
\alpha_{2}=\mathrm{Nu}_{\text {air }} \times \lambda_{\text {air }} / \mathrm{d}_{\mathrm{G}},
$$

where $\lambda_{\text {air }}-$ the thermal conductivity of air; Nusselt number $-\mathrm{Nu}_{\text {air }}=\operatorname{StPr}_{\text {air }}{ }^{2 / 3} \operatorname{Re}_{\text {air }} \operatorname{Pr}_{\text {air }}{ }^{1 / 3}$, where $\mathrm{StPr}_{\text {air }}{ }^{2 / 3}=-7,5 \cdot 10^{-7} \operatorname{Re}_{\text {air }}+0.0135$; where $\lambda_{\text {air }}, \rho_{\text {air }}$ и $\operatorname{Pr}_{\text {air }}$ parameters are determined by $t_{\text {a.a }}$ и $p_{\text {b. }}$. Reduced heat-exchange coefficient from the ribs to the air $\alpha_{\mathrm{R}}=\alpha_{\text {air }}[(\varphi-1) E+1] / \varphi, \mathrm{W} / \mathrm{m}^{2} \mathrm{~K}$, where the coefficient of the fins $\varphi=1+2 h\left(d_{\text {out }}+h+\Delta\right) /\left(S \cdot d_{\text {out }}\right)$.

16. The heat transfer coefficient, $\mathrm{W} / \mathrm{m}^{2} \mathrm{~K}$

$$
K=\left[\frac{1}{\alpha_{\text {average }}}+\left(R_{\text {Thml }}+R_{\text {Salt }} \frac{d_{\text {in }}}{d_{\text {out }}}+\frac{d_{\text {in }}}{2 \lambda_{\text {Thml }}} \ln \left(\frac{d_{B H}}{d_{H}}\right)+\frac{1}{\alpha_{I}} \cdot \frac{d_{\text {in }}}{d_{\text {out }}}\right) \varphi\right],
$$

where $R_{\mathrm{Thml}}$ - thermal resistance of a contact tube-fin $\mathrm{m}^{2} \mathrm{~K} / \mathrm{W} ; R_{\text {Salt }}-$ thermal resistance of the saline deposit inside the pipe, $\mathrm{m}^{2} \mathrm{~K} / \mathrm{W}$.

17. The estimated end temperature difference:

$$
\theta_{\mathrm{d}}=\left(t_{\mathrm{C}}-t_{\text {o.a. }}\right) \exp \left[-K \cdot F /\left(10^{3} c_{\text {air }} \cdot G_{\text {air }}\right)\right] \text {. }
$$

18. The air temperature at the output section:

$$
t_{\text {air } 2}{ }^{\prime}=t_{\mathrm{C}}-\theta_{\mathrm{d}},{ }^{\circ} \mathrm{C} \text {. }
$$

19. The end of the calculation occurs on the condition:

$$
\left|t_{\text {air } 2}{ }^{\prime}-t_{\text {air2 }}{ }^{\prime \prime}\right|<0.01{ }^{\circ} \mathrm{C} \text {. }
$$

If this condition is not satisfied, the steam flow rate $G_{\text {пा }}$ changes and the calculation process is repeated from step 4.

On the basis of the model in the package Excel spreadsheet developed calculation program by AC section where the physical parameters of the test substances are determined by the functions of the dynamic properties of the materials library «REFPROP»[6]. Automation closing a balance heat balance between steam and air produced by the method of bisection.

For research and testing program were chosen ammonia, hydrocarbons: isobutene, pentane, methanol and Freon (R236fa, R245fa). 
The initial data taken parameters of the standard section [4]: $L=12 \mathrm{~m} ; B=1.85 \mathrm{~m} ; Z=6$; the number of pipes in the section $N=132$; pipe material - steel 20, material fins - duralumin; type fins round; $D=0.057 \mathrm{~m} ; h=0.015 \mathrm{~m} ; d_{\text {out }}=0.027 \mathrm{~m} ; \delta=0,002 \mathrm{~m} ; \Delta=0.000735 \mathrm{~m} ; S=0,0025 \mathrm{~m} ; S_{1}=$ $0.084 \mathrm{~m}$. The air velocity in the section adopted $\omega_{\text {air }}=6 \mathrm{~m} / \mathrm{s}$; condensing temperature of halocarbon is $20{ }^{\circ} \mathrm{C}$ above $t_{\text {o.a. }}$; barometric pressure $98 \mathrm{kPa}$; the degree of dryness steam at the input equals 1 , at the output -0 .

Calculations were performed with change of the outdoor temperature in the range from -40 to +40 ${ }^{\circ} \mathrm{C}$. The calculation results are shown in Fig. 3, 4 .

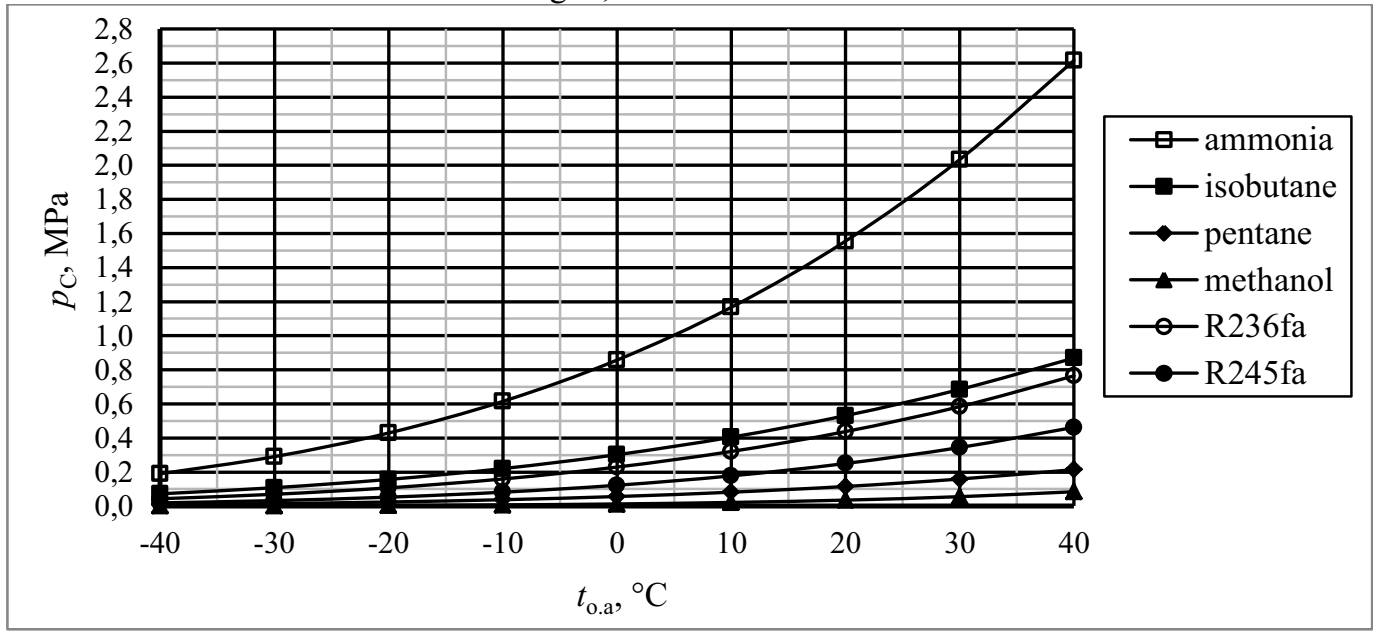

Figure 3. Functional connection $p_{c}$ from $t_{\text {o.a. }}$

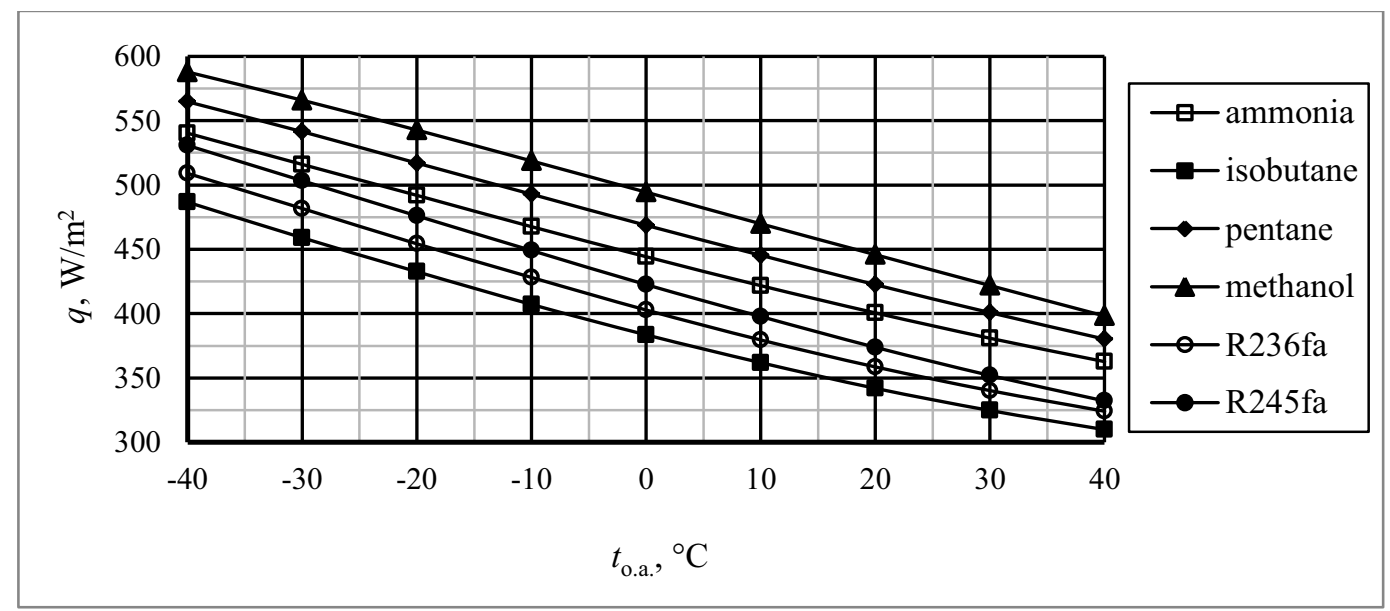

Figure 4. Functional connection $q$ from $t_{\text {o.a. }}$

\section{Analysis of the results numerical investigations}

The calculations allow to analyze the performance the section the AC to selected substances. Fig. 3 shows that with increasing outdoor temperature condensing pressure of all substances increases parabolic relationship. The highest pressure and the highest growth rate we can see at the ammonia. The lowest pressure and the lowest growth rate we can see at the methanol. The ammonia has the condensation pressure above atmospheric pressure in all range. At the others substances is observed only at a $\mathrm{t}_{\text {o.a. }}$ above: $-33{ }^{\circ} \mathrm{C}$ by isobutene; $-20{ }^{\circ} \mathrm{C}$ by $\mathrm{R} 236 \mathrm{fa} ; 0{ }^{\circ} \mathrm{C}$ by $\mathrm{R} 245 \mathrm{fa} ; 20{ }^{\circ} \mathrm{C}$ by pentane; methanol in all range $t_{\text {o.a. }}$ condensing pressure lower than atmospheric pressure. 


\section{MATEC Web of Conferences}

Fig. 4 describing efficacy the heat exchange section AC. On the effectiveness of the substance in the following order: methanol, pentane, ammonia, R245fa, R236fa, isobutene. When changing $\mathrm{t}_{\mathrm{o} . \mathrm{a}}$. from -40 to $+40{ }^{\circ} \mathrm{C}, q$ drop by $175 \div 185 \mathrm{~W} / \mathrm{m}^{2}$. Fig. 4 allows to determine from the heat flow AC required number of sections and the investment in the condenser. Then q must be chosen based on the $t_{\text {o.a. }}$ of the climatic region where installed AC.

\section{Conclusion}

The numerical studies have shown:

- Specifications and performance indicators the AC are highly dependent on the kind of substance.

- When the outdoor temperature changing from -40 to $40{ }^{\circ} \mathrm{C}$ specific heat flow in the AC drops on $175 \div 185 \mathrm{~W} / \mathrm{m}^{2}$.

- The model allows to determine from the known heat flow required number of units and investments in the condenser. This heat flow is necessary to select the temperature of outside air considering the climatic region installation AC.

The work has been done in framework of federal focused program implementation "Competitiveness Enhancement Program” of National Research Tomsk Polytechnic University.

\section{References}

1. A. Klevtsov, V. Pronin. URL: http://nst.e-apbe.ru/book/6.4.1.pdf (2015)

2. A. Milman, V. Fedorov, Air Condensing Units (Moscow, Moscow Power Engineering Institute, 2002)

3. N. Galashov, S. Tsibulskii, Power Technology and Engineering, 48, 6 (2015)

4. A. Besson Dreyner G., B. Kuntysh, Fundamentals of calculation and design of air-cooled heat exchangers (St. Petersburg, Nedra, 1996)

5. G. Kruzhilin, L. Boiko, Proceedings of the USSR Academy of Sciences. Energy and transport, 5 (1966)

6. E. Lemmon, M. Huber, M. McLinden, Reference fluid thermodynamic and transport propertiesREFPROP, standard reference database 23, version 8.0 (National Institute of Standard and Technology, 2007) 